\title{
Coronavirus: Crónica de una zoonosis anunciada
}

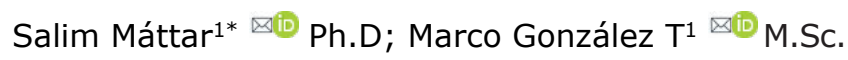

${ }^{1}$ Universidad de Córdoba, Facultad de Medicina Veterinaria y Zootecnia, Instituto de Investigaciones Biológicas del Trópico, Montería. Colombia.

*Correspondencia: mattarsalim@hotmail.com

Desde hace algunos años el espacio editorial de la Revista MVZ Córdoba se ha orientado hacia el abordaje de temas de salud pública humana y animal bajo el concepto "One Health". Hemos valorado y analizado artículos científicos, emitido opiniones, suscitado debates, propuestas de líneas de investigación y también hemos pronosticado y advertido de la llegada de nuevas enfermedades tanto al país como al continente.

Sin pretender relacionar cronológicamente todos estos hechos, en el 2005 se informaron los primeros casos de equinos positivos al virus del Oeste del Nilo (VON) y esos datos serológicos fueron considerados evidencia indirecta de actividad del VON en Colombia y en América del Sur. En ese entones, alertamos a las autoridades colombianas de salud humana y animal para mejorar la vigilancia de las enfermedades humanas atribuibles al VON (1).

En el 2008 se percibía el asombro y cierta impotencia de los investigadores en salud pública para enfrentar las nuevas cepas virales como los coronavirus asiáticos, virus de Chikunguña, así como los virus H1N1 y H5N1. En ese mismo contexto se comentó sobre la eficiente "reacomodación genética viral" y el posible salto interespecies desde huéspedes animales a Homo sapiens (2).

Las enfermedades zoonóticas representan el $78 \%$ de las enfermedades consideradas emergentes y reemergentes. Los virus participan en estas zoonosis en una alta proporción y con frecuencia aparecen nuevos virus produciendo una alta morbilidad y mortalidad; con el agravante que no existe un tratamiento. Por ejemplo, las primeras infecciones en humanos con el nuevo virus de influenza aviar A (H7N9) aparecieron en China en el 2013. El virus fue detectado en aves de corral y el $77 \%$ de las personas infectadas tuvieron contacto con aves de corral (3). Para la época expresamos nuestra preocupación en lo que podría suceder América Latina, porque las aves migratorias pueden llegar a nuestros territorios y propagar el virus a las aves domésticas y autóctonas, advirtiendo las debilidades de Colombia y los países del neotrópico para enfrentar esta enfermedad zoonótica (3).

En el 2014 alertamos sobre la inminente llegada a Colombia del virus Chikunguña (CHIKV), planteando, además, que este virus tenía mayores retos que el dengue, basados en el impacto que tuvo en otros países, en especial por el prolongado ausentismo laboral debido a las incapacidades laborales relacionadas con artritis y artralgias que podían durar semanas, meses o incluso, años (4). Efectivamente el CHIKV llegó aproximadamente siete meses después de haber publicado nuestro editorial en la población de San Joaquín, municipio de Mahates, Bolívar, Colombia. 
Para el año 2015 le tocó el turno al virus zika (ZIKV) y con base en los acontecimientos de la Polinesia, en donde circulaban simultáneamente dengue, Chikunguña y ZIKV, lo más probable era que muy pronto se viviría el arribo del ZIKV a Colombia, tal como finalmente también sucedió (5).

Para finales del año 2018 publicamos el editorial "Zoonotic emergence of coronavirus: a potential public risk for Latin America" (6), en donde mencionamos los primeros coronavirus detectados en humanos (HCoV-229E y HCoV-OC43) y que son causantes de enfermedades respiratorias leves. También se hizo referencia a los dos coronavirus más recientes, SARS-Coronavirus (SARS-CoV) y Mers-Coronavirus (MERS-CoV), pero a diferencia de los primeros, estos si causan con frecuencia una enfermedad grave. El SARS -CoV apareció en Guangdong, sur de China en el 2002 y fue el responsable de la primera pandemia del siglo XXI; los murciélagos fueron identificados como el reservorio y la fuente probable del brote. En 2012 se manifestó el MERS-CoV, en el Medio Oriente y los camellos fueron implicados como potenciales responsables.

Basados en las evidencias científicas consultadas, advertimos también que la familia Coronaviridae tenía un alto potencial zoonótico, ya que además de infectar aves, murciélagos y camellos, también habia afectado cerdos, pavos, perros, caballos, gatos, entre otros, y por tanto, sugeríamos incrementar la búsqueda de reservorios en animales salvajes, en especial porque se demostró que los coronavirus de los murciélagos fueron la fuente de muchos coronavirus humanos, incluidos SARS-CoV, MERSCoV, HCoV-229E y NL63.

Un año después, nuestro temor se hizo realidad cuando apareció el brote de COVID-19 en China. La verdad pensamos que iba ha quedar circunscrito en el oriente asiático como el SARS. Este virus emergente SARS-CoV2 tiene un alto potencial de transmisibilidad que ha desbordado los protocolos sanitarios causando una rápida expansión global de la enfermedad.

En Colombia se reportó el primer caso importado el 6 de marzo de 2020 y en el departamento de Córdoba, costa Caribe, se informó el primer diagnóstico el 29 de marzo. En Colombia se ha expandido a mas de 30 territorios (departamentos), incluida Bogotá, y ha infectado a 18.330 personas, de las cuales se han recuperado 4.431 y han fallecido 652 de ellas (mayo 21/20).

Ante la emergencia sanitaria y por cosas del destino, hoy, el único laboratorio de diagnóstico autorizado por el Instituto Nacional de Salud (INS) para realizar diagnóstico de COVID-19 en el departamento de Córdoba, es el del Instituto de Investigaciones Biológicas del Trópico (IIBT), perteneciente a la Universidad de Córdoba. Este aval es un reconocimiento al IIBT que lleva más de dos décadas investigando las enfermedades infecciosas emergentes y remergentes transmitidas por vectores (ETV) y ha contribuido con el conocimiento sobre los síndromes febriles relacionados con las ETV en humanos. El grupo de investigadores ha estudiado sobre vectores importantes en salud pública como: roedores, garrapatas, mosquitos y murciélagos. Las principales investigaciones y sus indicadores académicos de la última década se encuentran disponibles en https://scholar.google.com/citations? $\underline{\mathrm{hl}=\text { es\&user }=\mathrm{A} 8 Z 0 \mathrm{~L} q 8 \mathrm{AAAAJ} \& \mathrm{view} \text { op }=\text { list works }}$

Con la participación desinteresada, pero decidida de profesores y estudiantes de postgrado, el departamento de Córdoba ha podido contar hasta la fecha con más de 800 diagnósticos oportunos por la rapidez en la entrega de resultados para su población. Esta entrega decidida del equipo humano es digna de ser reconocida como ejemplo de solidaridad y profesionalismo con nuestros congéneres.

Desde este atril seguiremos muy atentos en nuestra tarea de vigilancia epidemiológica regional, nacional y global. Esperamos que en lo que resta del presente año se pueda encontrar la solución médica a esta terrible pandemia que tanto daño ha causado a la población mundial y a sus economías. Seamos optimistas que la ciencia con seguridad encontrará una pronta solución. 


\section{REFERENCIAS}

1. Mattar S, Edwards E, Laguado J, González TM, Alvarez J, Komar N. West Nile Virus Antibodies in Colombian Horses. Emerging Infectious Diseases. 2005; 11(9):14971498. https://dx.doi.org/10.3201/ eid1109.050426.

2. González TM, Máttar S. Estilos modernos de vida, cambio climático y ecosistemas alterados: un desastre anunciado para el surgimiento de las enfermedades infecciosas. Rev MVZ Córdoba. 2009; 14(2):1665-1666. https://doi.org/10.21897/rmvz.1000

3. Máttar S, González TM. Emerging zoonosis of a novel avian influenza A (H7N9) Virus. Are we prepared in the neotropics? Rev.MVZ Córdoba. 2013; 18(2):3437-3438, 2013. https://doi.org/10.21897/rmvz.164
4. Máttar S, González TM. Virus Chikungunya in Colombia, a simple matter of time? Rev MVZ Córdoba. 2014; 19(2):4045-4046. https:// doi.org/10.21897/rmvz.98

5. Máttar S, González TM. El turno ahora es para el virus Zika. Rev MVZ Córdoba. 2015; 20(2):4511-4512. https://doi. org/10.21897/rmvz.53

6. Máttar S, González TM. Zoonotic emergence of coronavirus: a potential public risk for Latin America. Rev MVZ Córdoba. 2018; 23(3):6775-6777. https://doi. org/10.21897/rmvz.1408 